\title{
Hormonally modulated migraine is associated with single-nucleotide polymorphisms within genes involved in dopamine metabolism
}

\author{
Amy K. Sullivan ${ }^{1 *}$, Elizabeth J. Atkinson ${ }^{2}$, F. Michael Cutrer ${ }^{1}$ \\ ${ }^{1}$ Division of Headache, Mayo Clinic, Rochester, USA \\ ${ }^{2}$ Division of Biomedical Statistics and Informatics, Mayo Clinic, Rochester, USA \\ Email: ${ }^{*}$ sullivan.amy@mayo.edu
}

Received 2 July 2013; revised 10 July 2013; accepted 20 July 2013

Copyright (C) 2013 Amy K. Sullivan et al. This is an open access article distributed under the Creative Commons Attribution License, which permits unrestricted use, distribution, and reproduction in any medium, provided the original work is properly cited.

\begin{abstract}
Migraine is a complex trait in which multiple genetic loci, as well as environmental factors, likely contribute to its clinical manifestation. Many genetic associations reported in previous studies either have not been replicated to date or showed only marginal statistical significance, possibly due to the genetic heterogeneity of the common forms of migraine. One major phenotypic and possibly genetically identifiable migraine subgroup consists of women whose attacks are influenced by fluctuation in gonadal hormones. We hypothesized that for these women, the association between migraine attacks and the menstrual cycle might be attributable to an increased prevalence of genetic polymorphisms in the hypothalamic-pituitary-gonadal axis. We selected 21 such polymerphisms previously reported to be associated with the common forms of migraine and genotyped 1740 individuals (1132 migraineurs) to determine whether any of these selected polymorphisms occurred more frequently in females with hormonally modulated migraine. We were able to confirm the association of migraine with 3 genetic polymorphisms seen in previous studies (rs4680 [COMT], rs2283265 [DRD2], and rs7131056 [DRD2]). Interestingly, we found 2 additional genetic polymorphisms (rs2070762 [TH] and rs6356 [TH]) to be associated with migraine when defining the phenotype as hormonally modulated migraine.
\end{abstract}

Keywords: Genetic Polymorphism; Headache; Hypothalamic Hormone; Menstrual Cycle; Menstruation

"Corresponding author.

\section{INTRODUCTION}

Migraine is a debilitating, heterogeneous neurologic disorder affecting over 35 million Americans $[1,2]$ and costing the American economy over 19 billion dollars annually $[3,4]$. Three-quarters of people with migraine are women $[1,2]$. Migraine is a complex trait in which multiple genetic loci, as well as environmental factors, likely contribute to its clinical manifestation [5]. Many genetic associations reported in previous studies either have not been replicated to date or showed only marginal statistical significance, possibly because of the genetic heterogeneity of common forms of migraine [6]. Given the clinical heterogeneity of migraine, it is important to clearly define the phenotype to better isolate the genetic component. One major phenotypic and possibly genetically identifiable migraine subgroup consists of women whose attacks are influenced by fluctuation in gonadal hormones. Given that almost $60 \%$ of women with migraine report that their attacks are more severe or frequent around the time of menstrual flow [7-10], variation in the genes coding for enzymes and receptors involved in the secretion and regulation of gonadal hormones may be a major source of migraine susceptibility.

Considerable circumstantial evidence implicates perturbation of the hypothalamic-pituitary-gonadal axis in migraine. Previous studies have shown that in some women, migraine attacks frequently are associated with dramatic decreases in estrogen during the menstrual cycle [11-13]. Furthermore, a rodent-based study showed enhanced sensitization of the trigeminal nucleus caudalis immediately after a decrease in ovarian hormone levels [14], consistent with differing trigeminal excitability among menstrual migraineurs [15].

Single-nucleotide polymorphisms (SNPs) rs1801132, rs2228480, and rs2234693 located within the estrogen 
receptor 1 gene (ESR1 [MIM 133430]), rs4986938 located within the estrogen receptor 2 gene (ESR2 [MIM 601663]), and rs1042838 located within the progesterone receptor gene (PGR [MIM 607311]) have been associated with migraine previously [16-21]. The physiology of the hypothalamic-pituitary-gonadal axis is complex, and although the nature of its exact interaction with migraine is not yet understood, the crosstalk between dopamine, norepinephrine, and endorphins (neurotransmitters involved in the hypothalamic-pituitary-gonadal axis and in pain) is well known [22-26]. In fact, after the estrogen is converted to catechol estrogen, the metabolism of gonadotropin-releasing hormone $(\mathrm{GnRH})$ and catecholamines are intimately influenced by one another. Catechol estrogens can inhibit tyrosine hydroxylase ( $T H$ [MIM 191290]) and compete for catechol-O-methyltransferase (COMT [MIM 116790]) (Figure 1) [26], indicating that estrogen levels may greatly influence catecholamine levels.

In previous studies, several genes involved in dopamine metabolism were implicated in migraine susceptibility. Genetic polymorphisms in COMT (rs4680), TH (rs 6356 and rs2070762), solute carrier family 6 member 3 (SLC6A3 [MIM 126455]) dopamine transporter (rs40184), dopa decarboxylase (DDC [MIM 107930]) (rs2329340), dopamine beta-hydroxylase ( $D B H$ [MIM 609312]) (rs 1611115 , rs2097629, and a 19-base pair insertion/deletion polymorphism [27] in the promoter region), and dopamine receptors D2 (DRD2 [MIM 126450]) (rs6275, rs1554929, rs2234689, rs2242592, rs2283265, rs7131056, and rs12363125) and D4 (DRD4 [MIM 126452]) (48base pair tandem repeat in exon III [28]) have been found to be associated with migraine [29-38]. However, the vast majority of SNP associations listed above have not been replicated [31].

In this study, we hypothesized that the association between migraine and the menstrual cycle might be attributable to increased prevalence of polymorphisms within genes involved in the hypothalamic-pituitary-gonadal axis (observed previously in male and female migraineurs). We selected 21 such polymorphisms previously reported to be associated with the common forms of migraine and genotyped 1740 individuals (1132 migraineurs) to determine whether any of these selected polymorphisms occurred more frequently in females with hormonally modulated migraine (HMM).

\section{METHODS}

\subsection{Study Population and Selection Criteria}

All individuals who participated in this study gave informed consent. The informed consent forms and protocols of this study were approved by the Mayo Clinic Institutional Review Board.

Migraine cases were ascertained using questionnaires based on the International Headache Society's diagnostic criteria (The International Classification of Headache Disorders, second edition [ICHD-II]) [39]. All elements
Catecholamines

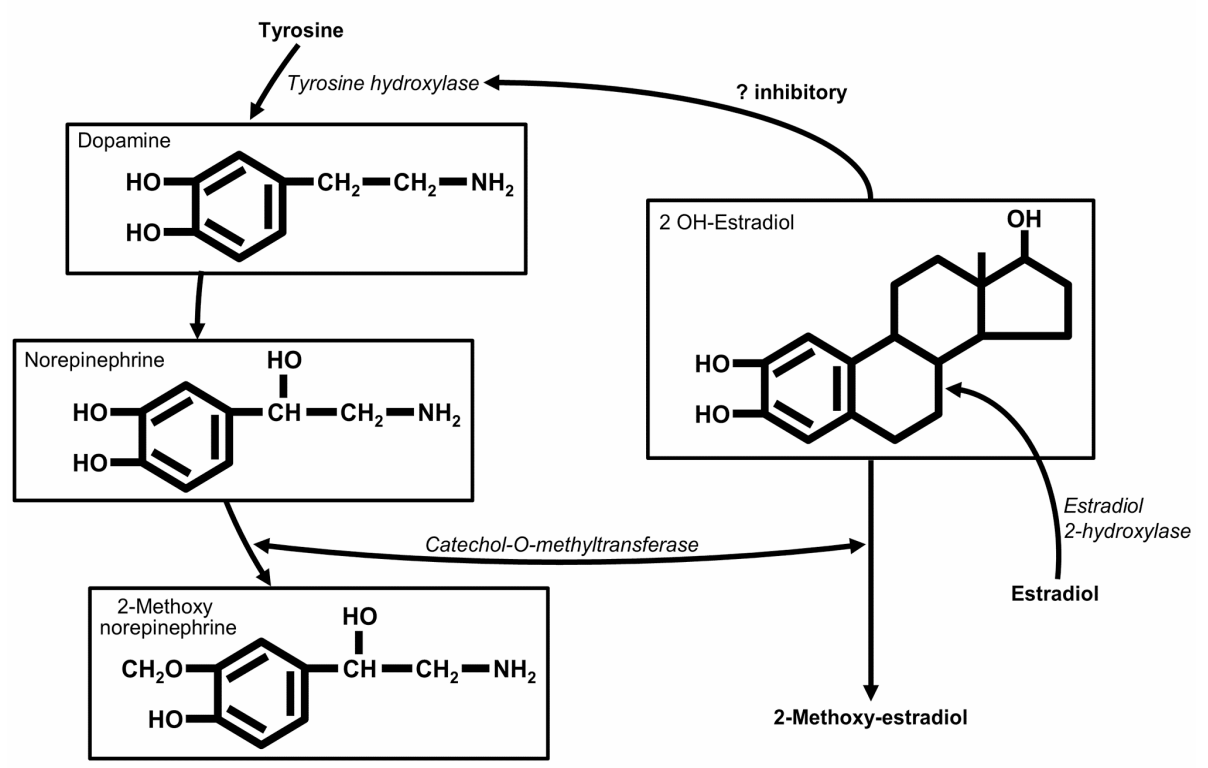

Figure 1. Catecholestrogens and their role in catecholamine metabolism. After estradiol is converted to catecholestrogen by estradiol 2-hydroxylase, the metabolism of gonadotropin-releasing hormone and catecholamines are intimately influenced by each other, as catecholestrogens can inhibit tyrosine hydroxylase and compete for catechol-O-methyltransferase (Adapted from Speroff and Fritz [26]. Used with permission). 
of the clinical phenotype were stored in the Mayo Headache Registry, a computerized data entry system that allows complex analysis of any data element, either separately or in tandem. Patients included in the Mayo Headache Registry were seen specifically for headache concerns in the outpatient setting in the Headache Division of the Neurology Department at Mayo Clinic (Rochester, Minnesota) or were volunteers (i.e., Mayo employees and trainees or local residents). Study subjects were recruited from 2006 through 2011. All questionnaires were completed in the presence of the investigators or study staff to address any questions raised by the subject. Blood samples were collected from individuals with migraines diagnosed on the basis of the ICHD-II [39] and were included in the Mayo Migraine Genomic Library, a DNA repository of migraine cases and age- and sex-matched controls.

Control subjects were recruited from the same volunteer pools as the case subjects. Individuals who qualified as control subjects had to indicate that they never had a migraine or probable migraine headache, as determined by their responses to a questionnaire administered by the study staff. Family history also was considered; only those subjects whose parents and siblings also had no history of migraine were included in the Mayo Migraine Genomic Library as controls.

Among the phenotypic data elements obtained from all female subjects was whether the migraine attacks occurred with greater frequency and intensity around the time of menstrual flow. The possible responses to this question were: 1) yes, the migraine attacks occur with greater frequency and intensity around the time of menstruation; 2) no, the migraine attacks do not occur with greater frequency and intensity around the time of menstruation; 3) I do not know; or 4) this question does not apply to me. Although human recall is imperfect, these 4 choices provide 2 answers for women who are unsure of the relationship of their attacks with menstruation; this increases the likelihood that the subjects are accurate in their response and minimizes recall bias.

The purpose of this study was to investigate the relationship between genotype and the phenotypic trait of menstrual modulation of migraine attacks, rather than to examine the characteristics of individual attacks. Thus, we opted not to use the ICHD-II appendix provisional diagnoses of pure menstrual migraine or menstrual-related migraine for this study because they required headaches to occur within 2 days (before or after) the first day of menstrual flow. Although such narrow definitions are important in therapeutic trials, they are not optimal in a large genetic-association study.

\subsection{Genetic Polymorphism Selection and Analysis}

We conducted a literature search and identified 21 poly- morphisms in genes involved in the hypothalamic-pituitary-gonadal axis, which drives menstrual flow [1621,27,29-36]; these polymorphisms previously were reported to be associated with the common forms of migraine (Table 1). We aimed to determine whether any of these associations held true in our study population.

Our initial analysis comparing cases and controls was performed using the entire dataset (males and females) to determine whether we could replicate findings found in previous studies. Our second analysis specifically considered only female cases and controls. Our third analysis compared women with nonhormonally modulated migraine (NHMM) vs female controls. Lastly, we compared women with HMM vs female controls.

\subsection{Genotyping}

DNA isolation was performed at the Biospecimens Accessing and Processing Core Facility at Mayo Clinic. Briefly, DNA from whole blood was purified using the Flex Star genomic DNA isolation instrument (Autogen, Inc) and the Flexigene DNA kit (Qiagen, Inc). Once purified, the DNA was quantified with a Nanodrop ND8000 spectrophotometer (Thermo Fisher Scientific, Inc).

The DNA samples were activated through a chemical reaction with biotin. Biotinylated DNA was purified to remove excess biotin. Assay oligonucleotides were hybridized to the DNA, and the mixture was bound to streptavidin-conjugated paramagnetic particles. Hybridized oligonucleotides underwent allele specific primer extension and ligation, and the products formed a synthetic template that was amplified via a polymerase chain reaction (PCR). The strand containing the fluorescent signal in the PCR products was isolated and hybridized to VeraCode universal capture bead sets (Illumina, Inc.) via an address sequence. The BeadXpress reader system and BeadStudio data analysis software (Illumina, Inc.) were used to automatically identify alleles. The genotype of the SNP was determined by the ratio of the relative fluorescent levels of the 2 bead types.

The variable number of tandem repeats (VNTR) polymorphisms in both the $D B H$ and $D R D 4$ genes was analyzed using a 3730XL DNA sequencer (Applied Biosystems, Inc.). Briefly, PCR amplification was performed using TaqGold, with specific primers to amplify the regions of interest (Applied Biosystems, Inc). For $D B H$ VNTR, the forward primer sequence was

5'-NEDAATCAGGCACATGCACCTCC-3', and the reverse primer sequence was

5'-GGCCCTGAGGAATCTTACAGG-3'. For DRD4 VNTR, PCR was performed with the primer set 5'-6FAM-AGGACCCTCATGGCCTTG-3' and 5'-GCGACTACGTGGTCTACTCG-3'. Genotypes were identified using GeneMapper software (Applied Biosystems, Inc). Allele identification was based on known ge- 
Table 1. Genetic polymorphisms in the hypothalamic-pituitary-gonadal axis previously reported to be associated with migraine.

\begin{tabular}{|c|c|c|c|c|}
\hline Reference SNP Number & Gene Name & Encoded Protein & Chromosome & Study \\
\hline rs 40184 & $S L C 6 A 3$ & $\begin{array}{l}\text { Solute carrier family } 6 \text { (neuro-transmitter } \\
\text { transporter, dopamine), member } 3\end{array}$ & 5 & 32 \\
\hline $\begin{array}{l}\text { rs } 1801132 \\
\text { rs2228480 } \\
\text { rs2234693 }\end{array}$ & ESR 1 & Estrogen receptor 1 & 6 & $\begin{array}{c}19 \\
17.21 \\
16\end{array}$ \\
\hline rs2329340 & $D D C$ & $\begin{array}{c}\text { Dopa decarboxylase } \\
\text { (aromatic L-amino acid decarboxylase) }\end{array}$ & 7 & 33 \\
\hline $\begin{array}{c}\text { rs1611115 } \\
\text { rs2097629 } \\
\text { Promoter region, } 19 \text { base pair } \\
\text { insertion/deletion }\end{array}$ & $D B H$ & $\begin{array}{c}\text { Dopamine beta-hydroxylase } \\
\text { (dopamine beta-mono-oxygenase) }\end{array}$ & 9 & $\begin{array}{c}34 \\
32 \\
35.36\end{array}$ \\
\hline $\begin{array}{c}\text { rs6275 } \\
\text { rs1554929 } \\
\text { rs2234689 } \\
\text { rs2242592 } \\
\text { rs2283265 } \\
\text { rs7131056 } \\
\text { rs12363125 }\end{array}$ & $D R D 2$ & Dopamine receptor D2 & 11 & $\begin{array}{l}38 \\
31 \\
31 \\
31 \\
31 \\
32 \\
31\end{array}$ \\
\hline $\begin{array}{l}\mathrm{rs} 6356 \\
\mathrm{rs} 2070762\end{array}$ & $T H$ & Tyrosine hydroxylase & 11 & $\begin{array}{l}31 \\
31\end{array}$ \\
\hline rs 1042838 & $P G R$ & Progesterone receptor & 11 & 16 \\
\hline Exon III, 48-base pair tandem repeat & $D R D 4$ & Dopamine receptor & 11 & 37 \\
\hline rs4986938 & ESR2 & Estrogen receptor 2 (ER beta) & 14 & 17 \\
\hline rs4680 & COMT & Catechol-O-methyltransferase & 22 & 29.30 \\
\hline
\end{tabular}

notype and size standards described in previous studies $[28,36]$.

\subsection{Statistical Analyses}

Before conducting statistical analyses, general quality control checks were performed on the genotype data. Polymorphisms with call rates less than 95\%, SNPs with minor allele frequencies less than $5 \%$, and polymerphisms that deviated from Hardy-Weinberg equilibrium $(P$ $<10^{-5}$ ) were closely examined because these are indicators of potential clustering problems. Samples with call rates less than $95 \%$ were excluded from the analysis. The association of each polymorphism with migraine was evaluated by logistic regression using age and sex as covariates to account for confounding variables. Di-allelic markers were tested using the additive genetic model, in which genotypes are coded as 0,1 , or 2 , according to the number of rare variants. The VNTR was tested using indicators for carrier status of the common variants and by using a single count for the number of repeats. The $t$ test and $\chi^{2}$ test were used to test for group differences of continuous and categorical variables, respectively.

\section{RESULTS}

\subsection{Study Population}

Our study population included 1740 subjects (1132 cases, 608 controls). Figure 2 shows how cases and controls were further divided into subgroups on the basis of sex and presence or absence of HMM. Age and race (percentage white) were similar between cases and controls (Table 2). Results remained statistically significant when conducting statistical analyses among whites only.

\subsection{Identification of SNPs Associated with Migraine}

Table 3 summarizes the SNPs with confirmed association with migraine. With logistic regression analyses applied to the full study cohort, we identified SNPs rs4680 (COMT), rs2283265 (DRD2), and rs7131056 (DRD2) as being associated with migraine. Considering the femaleonly subgroup, rs4680 (COMT) was still significantly associated with migraine. No SNPs were associated with migraine when comparing females with NHMM $(\mathrm{n}=364)$ vs controls $(\mathrm{n}=350)$; specifically, the COMT SNP rs 4680 was not significantly associated with migraine in this subgroup (odds ratio, $1.18 ; 95 \% \mathrm{CI}, 0.95-1.42 ; P=$ 0.13).

When comparing women with HMM vs female controls, we again identified SNPs from COMT and DRD2. However, we also identified 2 additional SNPs, rs2070762 and rs6356 (both within $T H$ ), as having significant association with migraine. Of note, SNP rs7131056 (DRD2) was not significantly associated with migraine in this subgroup (OR, 1.10; 95\% CI, $0.90-1.35 ; P=0.35$ ). 
Table 2. Study population characteristics.

\begin{tabular}{cccccccc}
\hline & \multirow{2}{*}{\begin{tabular}{c} 
All \\
\cline { 3 - 7 }
\end{tabular}} & \multicolumn{2}{c}{ Controls } & \multicolumn{3}{c}{ Cases } \\
\cline { 3 - 7 } & & $\begin{array}{c}\text { All } \\
(\mathbf{n}=\mathbf{6 0 8})\end{array}$ & $\begin{array}{c}\text { Females } \\
(\mathbf{n}=\mathbf{3 5 0})\end{array}$ & $\begin{array}{c}\text { All } \\
(\mathbf{n}=\mathbf{1 1 3 2})\end{array}$ & $\begin{array}{c}\text { Females } \\
(\mathbf{n}=\mathbf{8 9 2})\end{array}$ & $\begin{array}{c}\text { HMM } \\
(\mathbf{n}=\mathbf{4 6 4})\end{array}$ & $\begin{array}{c}\text { NHMM } \\
(\mathbf{n}=\mathbf{3 6 4})\end{array}$ \\
\hline Age, mean (SD), y & $33.89(8.22)$ & $34.49(8.09)$ & $34.71(7.95)$ & $33.57(8.27)$ & $33.30(7.90)$ & $34.72(7.81)$ & $32.07(7.87)$ \\
Range & $18-50$ & $19-50$ & $21-50$ & $18-50$ & $18-50$ & $18-50$ & $18-49$ \\
White race, No. (\%) & $1651(94.89)$ & $555(91.29)$ & $333(95.14)$ & $1096(96.82)$ & $867(97.20)$ & $452(97.41)$ & $351(96.43)$ \\
\hline
\end{tabular}

Abbreviations: HMM, hormonally modulated migraine; NHMM, nonhormonally modulated migraine.

Table 3. SNPs associated with migraine.

\begin{tabular}{|c|c|c|c|c|c|}
\hline Group & Cases, No. & Controls, No. & SNP (Gene) & Odds Ratio (95\% CI) & $P$ Value \\
\hline All cases $(\mathrm{N}=1740)$ & 1132 & 608 & $\begin{array}{c}\text { rs4680 (COMT) } \\
\text { rs2283265 (DRD2) } \\
\text { rs7131056 (DRD2) }\end{array}$ & $\begin{array}{l}1.25(1.09-1.45) \\
1.22(1.01-1.47) \\
1.18(1.03-1.35)\end{array}$ & $\begin{array}{c}0.001 \\
0.04 \\
0.02\end{array}$ \\
\hline Females only $(n=1242)$ & 892 & 350 & rs4680 (COMT) & $1.2(1.02-1.43)$ & 0.03 \\
\hline HMM vs female controls $(n=814)$ & 464 & 350 & $\begin{array}{c}\text { rs4680 (COMT) } \\
\text { rs2283265 (DRD2) } \\
\text { rs2070762(TH) } \\
\text { rs6356 (TH) }\end{array}$ & $\begin{array}{l}1.23(1.02-1.52) \\
1.37(1.05-1.82) \\
1.23(1.01-1.49) \\
1.24(1.01-1.53)\end{array}$ & $\begin{array}{l}0.03 \\
0.02 \\
0.04 \\
0.04\end{array}$ \\
\hline
\end{tabular}

Abbreviations: HMM, hormonally modulated migraine; SNP, single-nucleotide polymorphism.

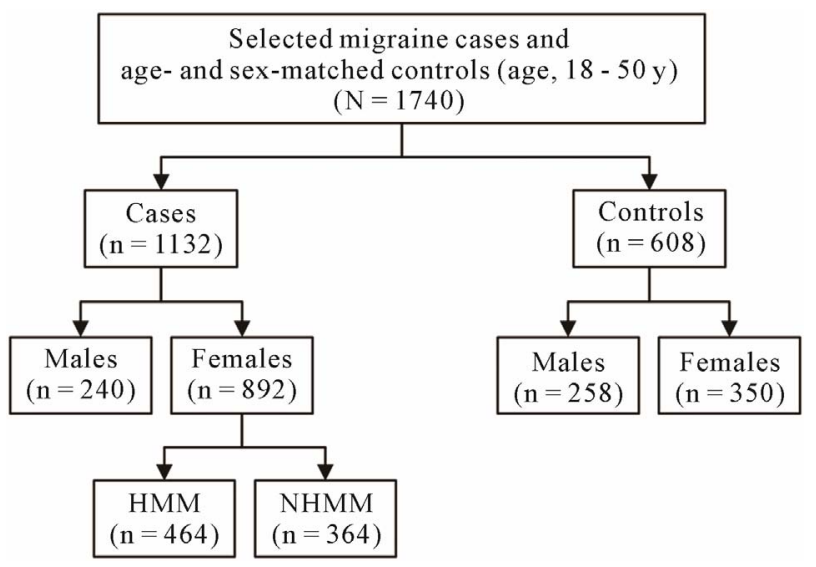

Figure 2. Study population. Blood samples were collected from individuals with a migraine diagnosis and from age- and sexmatched controls. Details of classification criteria are described in the Methods. HMM denotes hormonally modulated migraine; NHMM, nonhormonally modulated migraine.

\section{DISCUSSION}

In our large cohort of 1740 individuals, we surveyed 21 genetic polymorphisms previously shown to be associated with migraine, with gene products that were involved in the hypothalamic-pituitary-gonadal axis. We were able to confirm the association of migraine with 3 SNPs: rs4680 (COMT), rs2283265 (DRD2), and rs7131056 (DRD2) $[29,30,32,40]$. To our knowledge, this is the first study to confirm these associations to date.

We then tested our hypothesis that the genetic polymorphisms previously reported to be associated with migraine were more common in females whose migraine attacks were influenced by their menstrual cycle. When we defined the clinical phenotype as women with HMM, 4 SNPs (rs4680, rs2283265, rs2070762, and rs6356) located within genes COMT, DRD2, and TH showed significant associations, even though the number of cases in the subgroup was smaller than the initial study group. However, the rs7131056 (DRD2) association was no longer significant in this subanalysis, possibly because of the smaller number of cases. No SNPs were found to be associated with migraine when cases were limited to women with NHMM.

By narrowing the study group to a more homogenous clinical migraine phenotype, we were able to better detect the association of several genetic polymorphisms with migraine. Our findings suggest that women with HMM may have an underlying pathophysiologic mechanism that is distinct from that of women whose migraines are not modulated by the hypothalamic-pituitary-gonadal axis. Conversely, these findings also suggest that women with NHMM may be a more genetically heterogeneous group, or at least their association with migraine is not based on variation in the hypothalamic-pituitary-gonadal axis-related genes that we studied.

Notably, all genetic polymorphisms found to be associated with migraine in the current study were involved in dopamine metabolism. Why might this be the case? One possibility is that dopamine metabolism is an important interface between the hypothalamic-pituitary-gonadal axis and pain modulation. Dopamine in the central nervous system is known to have a role in pain modulation $[40,41]$ and in fact has been implicated in migraine pathophysiology [42]. In rodent models, dopamine can block nociceptive signal transmission at the level of the trigeminocervical complex by binding D2-like receptors 
[43]. Also, trigeminal nociceptive transmission is influenced by the dopaminergic A11 nucleus [44]. Other key players in dopamine metabolism have also been shown to affect pain modulation. Inhibition of COMT increased pain sensitization in mice [45], and stress-induced analgesia was altered in COMT-deficient mice [46].

Dopamine is important not only in pain modulation but also in the catechol estrogen metabolism pathway. Specifically, in the brain, estrone and estradiol can be converted into catechol estrogens by 2-hydroxylase. At the level of the anterior pituitary, catechol estrogens may compete with dopamine for dopamine-binding sites and may even inhibit the synthesis and metabolism of dopamine [47]. In rats, catechol estrogens decrease the turnover rate of dopamine in the corpus striatum [48]. Also, animal studies have shown that dopamine influences GnRH production at the level of the hypothalamus [4952]. In fact, in vitro data suggest that dopamine can stimulate GnRH secretion from the human hypothalamus [53]. Some evidence suggests that D1 receptor stimulation increases pituitary responsiveness to GnRH in women [54]. Clearly, dopamine and estrogen pathways are intimately associated on several levels, which may explain the association of dopamine-related genetic polymorphisms with migraine in women whose headaches are influenced by their menstrual cycles.

As with other complex traits, clinical heterogeneity confounds identification of the genetic underpinnings of migraine. Thus, careful detailed ascertainment of clinical phenotype in the sample population is likely to be of great importance. The ability to segregate case subjects into more clinically homogenous groups on the basis of biologic characteristics may prove invaluable for unraveling the genetic components of complex traits such as migraine.

A possible weakness of our study was the relative lack of ethnic diversity in our cohort. Migraine affects individuals across all racial groups. However, given our geographic location (Rochester, Minnesota), greater than $90 \%$ of subjects were white in both the case and control groups, and the remaining subjects comprised more than 20 different ethnicities. Nevertheless, when conducting statistical analyses among whites only, our results remained statistically significant.

In this study, by defining the clinical phenotype as women with HMM, we were better able to identify additional associated genetic polymorphisms. Intriguingly, all the genetic polymorphisms that we identified or confirmed as significantly associated with migraine were in genes involved in dopamine metabolism. Dopamine is important not only in pain modulation but also in catechol estrogen metabolism. The importance of dopamine in migraine may be due to its function at the interface of the hypothalamic-pituitary-gonadal axis and pain modulation. More studies investigating this association are needed.

\section{ACKNOWLEDGEMENTS}

This work was supported through a grant from the Mayo Clinic Women's Health Research program. We would also like to express our appreciation to the Mayo Clinical Research Fund, GlaxoSmithKline, the Migraine Research Foundation, and Mary Ella Jerome for their unrestricted support of the Mayo Migraine Genomic Library.

\section{REFERENCES}

[1] Lipton, R.B., Bigal, M.E., Diamond, M., Freitag, F., Reed, M.L. and Stewart, W.F. (2007) Migraine prevalence, disease burden, and the need for preventive therapy. Neurology, 68, 343-349. doi:10.1212/01.wnl.0000252808.97649.21

[2] Lipton, R.B. and Stewart, W.F. (1997) Prevalence and impact of migraine. Neurologic Clinics, 15, 1-13. doi:10.1016/S0733-8619(05)70291-7

[3] Hawkins, K., Wang, S. and Rupnow, M.F. (2007) Indirect cost burden of migraine in the United States. Journal of Occupational and Environmental Medicine, 49, 368374. doi:10.1097/JOM.0b013e31803b9510

[4] Hawkins, K., Wang, S. and Rupnow, M. (2008) Direct cost burden among insured US employees with migraine. Headache, 48, 553-563. doi:10.1111/j.1526-4610.2007.00990.x

[5] Mulder, E.J., Van Baal, C., Gaist, D., Kallela, M., Kaprio, J., Svensson, D.A, et al. (2003) Genetic and environmental influences on migraine: A twin study across six countries. Twin Research, 6, 422-431.

[6] Wessman, M., Terwindt, G.M., Kaunisto, M.A., Palotie, A. and Ophoff, R.A. (2007) Migraine: A complex genetic disorder. Lancet Neurology, 6, 521-532. doi:10.1016/S1474-4422(07)70126-6

[7] Couturier, E.G., Bomhof, M.A., Neven, A.K. and van Duijn, N.P. (2003) Menstrual migraine in a representative Dutch population sample: Prevalence, disability and treatment. Cephalalgia, 23, 302-308. doi:10.1046/j.1468-2982.2003.00516.x

[8] Gupta, S., Mehrotra, S., Villalon, C.M., Perusquia, M., Saxena, P.R. and Maassen Van Den Brink, A. (2007) Potential role of female sex hormones in the pathophysiology of migraine. Pharmacology \& Therapeutics, 113, 321-340. doi:10.1016/j.pharmthera.2006.08.009

[9] MacGregor, E.A., Chia, H., Vohrah, R.C. and Wilkinson, M. (1990) Migraine and menstruation: A pilot study. Cephalalgia, 10, 305-310. doi:10.1046/j.1468-2982.1990.1006305.x

[10] MacGregor, E.A. (2004) Oestrogen and attacks of migraine with and without aura. Lancet Neurology, 3, 354361. doi:10.1016/S1474-4422(04)00768-9

[11] Martin, V.T. and Lipton, R.B. (2008) Epidemiology and biology of menstrual migraine. Headache, 48, S124S130. doi:10.1111/j.1526-4610.2008.01310.x

[12] MacGregor, E.A. (1996) "Menstrual” migraine: Towards 
a definition. Cephalalgia, 16, 11-21. doi:10.1046/j.1468-2982.1996.1601011.x

[13] Stewart, W.F., Lipton, R.B., Chee, E., Sawyer, J. and Silberstein, S.D. (2000) Menstrual cycle and headache in a population sample of migraineurs. Neurology, 55, 15171523. doi:10.1212/WNL.55.10.1517

[14] Martin, V.T., Lee, J. and Behbehani, M.M. (2007) Sensitization of the trigeminal sensory system during different stages of the rat estrous cycle: Implications for menstrual migraine. Headache, 47, 552-563.

[15] Varlibas, A. and Erdemoglu, A.K. (2009) Altered trigeminal system excitability in menstrual migraine patients. Journal of Headache and Pain, 10, 277-282. doi:10.1007/s10194-009-0132-4

[16] Joshi, G., Pradhan, S. and Mittal, B. (2010) Role of the oestrogen receptor (ESR1 PvuII and ESR1 $325 \mathrm{C}->\mathrm{G}$ ) and progesterone receptor (PROGINS) polymorphisms in genetic susceptibility to migraine in a North Indian population. Cephalalgia, 30, 311-320.

[17] Oterino, A., Toriello, M., Cayon, A., Castillo, J., Colas, R., Alonson-Arranz, A., et al. (2008) Multilocus analyses reveal involvement of the ESR1, ESR2 and FSHR genes in migraine. Headache, 48, 1438-1450. doi:10.1111/j.1526-4610.2008.01294.x

[18] Lee, H., Sininger, L., Jen, J.C., Cha, Y.H., Baloh, R.W. and Nelson, S.F. (2007) Association of progesterone receptor with migraine-associated vertigo. Neurogenetics, $\mathbf{8}$, 195-200. doi:10.1007/s10048-007-0091-3

[19] Oterino, A., Pascual, J., Ruiz de Alegria, C., Valle, N., Castillo, J., Bravo, Y., et al. (2006) Association of migraine and ESR1 G325C polymorphism. NeuroReport, 17, 61-64. doi:10.1097/01.wnr.0000192735.85287.f4

[20] Colson, N.J., Lea, R.A., Quinlan, S., MacMillan, J. and Griffiths, L.R. (2005) Investigation of hormone receptor genes in migraine. Neurogenetics, 6, 17-23. doi:10.1007/s10048-004-0205-0

[21] Colson, N.J., Lea, R.A., Quinlan, S., MacMillan, J. and Griffiths, L.R. (2004) The estrogen receptor 1 G594A polymorphism is associated with migraine susceptibility in two independent case/control groups. Neurogenetics, $\mathbf{5}$, 129-133. doi:10.1007/s10048-004-0181-4

[22] Silberstein, S.D. and Merriam, G.R. (2000) Physiology of the menstrual cycle. Cephalalgia, 20, 148-154. doi:10.1046/j.1468-2982.2000.00034.x

[23] Zacur, H.A. (2006) Hormonal changes throughout life in women. Headache, 46, S49-S54. doi:10.1111/j.1526-4610.2006.00554.x

[24] Martin, V.T. and Behbehani, M. (2006) Ovarian hormones and migraine headache: Understanding mechanisms and pathogenesis: Part I. Headache, 46, 3-23. doi:10.1111/j.1526-4610.2006.00309.x

[25] Martin, V.T. and Behbehani, M. (2006) Ovarian hormones and migraine headache: Understanding mechanisms and pathogenesis: Part 2. Headache, 46, 365-386. doi:10.1111/j.1526-4610.2006.00370.x

[26] Speroff, L. and Fritz, M.A. (2005) Clinical Gynecologic Endocrinology and Infertility. 7th Edition, Lippincott Williams \& Wilkins, Philadelphia.
[27] Nahmias, J., Burley, M.W., Povey, S., Porter, C., Craig, I. and Wolfe, J. (1992) A 19 bp deletion polymorphism adjacent to a dinucleotide repeat polymorphism at the human dopamine beta-hydroxylase locus. Human Molecular Genetics, 1, 286. doi:10.1093/hmg/1.4.286

[28] Ebstein, R.P., Novick, O., Umansky, R., Priel, B., Osher, Y., Blaine, D., et al. (1996) Dopamine D4 receptor (D4DR) exon III polymorphism associated with the human personality trait of Novelty Seeking. Nature Genetics, 12, 78-80. doi:10.1038/ng0196-78

[29] Emin Erdal, M., Herken, Y., Yilmaz, M. and Bayazit, Y.A. (2001) Significance of the catechol-O-methyltransferase gene polymorphism in migraine. Brain Research. Molecular Brain Research, 94, 193-196. doi:10.1016/S0169-328X(01)00219-4

[30] Park, J.W., Lee, K.S., Kim, J.S., Kim, Y.I. and Shin, H.E. (2007) Genetic contribution of catechol-o-methyltransferase polymorphism in patients with migraine without aura. Journal of Clinical Neurology, 3, 24-30. doi:10.3988/jen.2007.3.1.24

[31] Corominas, R., Ribases, M., Camina, M., Cuenca-Leon, E., Pardo, J., Boronat, S., et al. (2009) Two-stage casecontrol association study of dopamine-related genes and migraine. BMC Medical Genetics, 10, 95. doi:10.1186/1471-2350-10-95

[32] Todt, U., Netzer, C., Toliat, M., Heinze, A., Goebel, I., Nurnberg, P., et al. (2009) New genetic evidence for involvement of the dopamine system in migraine with aura. Human Genetics, 125, 265-279. doi:10.1007/s00439-009-0623-z

[33] Corominas, R., Sobrido, M.J., Ribases, M., Cuenca-Leon, E., Blanco-Arias, P., Narberhaus, B., et al. (2010) Association study of the serotoninergic system in migraine in the Spanish population. American Journal of Medical Genetics. Part B, Neuropsychiatric Genetics, 153B, 177184.

[34] Fernandez, F., Colson, N., Quinlan, S., MacMillan, J., Lea, R.A. and Griffiths, L.R. (2009) Association between migraine and a functional polymorphism at the dopamine beta-hydroxylase locus. Neurogenetics, 10, 199-208. doi:10.1007/s10048-009-0176-2

[35] Fernandez, F., Lea, R.A., Colson, N.J., Bellis, C., Quinlan, S. and Griffiths, L.R. (2006) Association between a 19 bp deletion polymorphism at the dopamine beta-hydroxylase (DBH) locus and migraine with aura. Journal of the Neurological Sciences, 251, 118-123. doi:10.1016/j.jns.2006.09.013

[36] Lea, R.A., Dohy, A., Jordan, K., Quinlan, S., Brimage, P.J. and Griffiths, L.R. (2000) Evidence for allelic association of the dopamine beta-hydroxylase gene (DBH) with susceptibility to typical migraine. Neurogenetics, $\mathbf{3}$, 35-40.

[37] Mochi, M., Cevoli, S., Cortelli, P., Pierangeli, G., Soriani, S., Scapoli, C., et al. (2003) A genetic association study of migraine with dopamine receptor 4, dopamine transporter and dopamine-beta-hydroxylase genes. Neurological Sciences, 23, 301-305. doi:10.1007/s100720300005

[38] Peroutka, S.J., Wilhoit, T. and Jones, K. (1997) Clinical susceptibility to migraine with aura is modified by dopa- 
mine D2 receptor (DRD2) NcoI alleles. Neurology, 49, 201-206. doi:10.1212/WNL.49.1.201

[39] Headache Classification Subcommittee of the International Headache Society (2004) The international classification of headache disorders. 2nd Edition, Cephalalgia, 24, 24-36.

[40] Wood, P.B. (2008) Role of central dopamine in pain and analgesia. Expert Review of Neurotherapeutics, 8, 781797. doi:10.1586/14737175.8.5.781

[41] Viisanen, H., Ansah, O.B. and Pertovaara, A. (2012) The role of the dopamine D2 receptor in descending control of pain induced by motor cortex stimulation in the neuronpathic rat. Brain Research Bulletin, 89, 133-143. doi:10.1016/j.brainresbull.2012.08.002

[42] Charbit, A.R., Akerman, S. and Goadsby, P.J. (2010) Dopamine: What's new in migraine? Current Opinion in Neurology, 23, 275-281. doi:10.1097/WCO.0b013e3283378d5c

[43] Bergerot, A., Storer, R.J. and Goadsby, P.J. (2007) Dopamine inhibits trigeminovascular transmission in the rat. Annals of Neurology, 61, 251-262. doi:10.1002/ana.21077

[44] Charbit, A.R., Akerman, S., Holland, P.R. and Goadsby, P.J. (2009) Neurons of the dopaminergic/calcitonin generelated peptide A11 cell group modulate neuronal firing in the trigeminocervical complex: An electrophysiological and immunohistochemical study. Journal of Neuroscience, 29, 12532-12541. doi:10.1523/JNEUROSCI.2887-09.2009

[45] Kambur, O., Talka, R., Ansah, O.B., Kontinen, V.K., Pertovaara, A., Kalso, E., et al. (2010) Inhibitors of catechol-O-methyltransferase sensitize mice to pain. British Journal of Pharmacology, 161, 1553-1565. doi:10.1111/j.1476-5381.2010.00999.x

[46] Kambur, O., Mannisto, P.T., Viljakka, K., Reenila, I., Lemberg, K., Kontinen, V.K., et al. (2008) Stress-induced analgesia and morphine responses are changed in
catechol-O-methyltransferase-deficient male mice. Basic \& Clinical Pharmacology \& Toxicology, 103, 367-373. doi:10.1111/j.1742-7843.2008.00289.x

[47] Knobil, E. and Neill, J.D. (1994) The physiology of reproduction. 2nd Edition, Raven Press, New York.

[48] Panek, D.U. and Dixon, W.R. (1986) Effect of continuous intraventricular estrogen or catechol estrogen treatment on catecholamine turnover in various brain regions. Journal of Pharmacology and Experimental Therapeutics, 236, 646-652.

[49] Marcano de Cotte, D., De Menezes, C.E., Bennett, G.W. and Edwardson, J.A. (1980) Dopamine stimulates the degradation of gonadotropin releasing hormone by rat synaptosomes. Nature, 283, 487-489. doi: $10.1038 / 283487 \mathrm{a} 0$

[50] Zohar, Y., Munoz-Cueto, J.A., Elizur, A. and Kah, O. (2010) Neuroendocrinology of reproduction in teleost fish. General and Comparative Endocrinology, 165, 438455. doi:10.1016/i.ygcen.2009.04.017

[51] Dufour, S., Sebert, M.E., Weltzien, F.A., Rousseau, K. and Pasqualini, C. (2010) Neuroendocrine control by dopamine of teleost reproduction. Journal of Fish Biology, 76, 129-160. doi:10.1111/j.1095-8649.2009.02499.x

[52] Popesku, J.T., Martyniuk, C.J., Denslow, N.D. and Trudeau, V.L. (2010) Rapid dopaminergic modulation of the fish hypothalamic transcriptome and proteome. PLoS One, 5, e12338. doi:10.1371/journal.pone.0012338

[53] Rasmussen, D.D., Liu, J.H., Wolf, P.L. and Yen, S.S. (1986) Gonadotropin-releasing hormone neurosecretion in the human hypothalamus: In vitro regulation by dopamine. Journal of Clinical Endocrinology and Metabolism, 62, 479-483. doi:10.1210/jcem-62-3-479

[54] Boesgaard, S., Hagen, C., Hangaard, J., Andersen, A.N. and Eldrup, E. (1991) Pulsatile gonadotropin secretion and basal prolactin levels during dopamine D-1 receptor stimulation in normal women. Fertility and Sterility, $\mathbf{5 5}$ 281-286. 